of periodontal disease on preeclampsia mediated by dissemination of gram-negative bacteria and secretion of proinflammatory cytokines (11), although reverse causation or a common inflammatory etiology also are discussed (12). In addition, maternal inflammatory bowel disease, which is associated with a skewed gut microbiome, has been reported as a risk factor for severe preeclampsia, particularly in severe cases requiring oral corticosteroid therapy (13).

The risk for preeclampsia decreases over subsequent pregnancies, as verified by Stokholm and colleagues (6). This is an intriguing parallel to the birth order effect of the hygiene hypothesis (14). Birth order has often been interpreted as number of (older) siblings, and thus as risk for infection by "unhygienic contact" (14). In the light of the present findings, however, the birth order effect might point toward an antiinflammatory effect of previous pregnancies $(2,5)$, and that in a dose-dependent manner.

Obviously, not all forms of asthma are likely to be induced by prenatal inflammation (1), and prenatal inflammation does not necessarily lead to subsequent asthma, as detrimental effects of prenatal inflammation might be overruled by antiinflammatory factors (Figure 1). Indeed, there is evidence for antiinflammatory effects by favorable environmental exposures pre- $(15)$ and postnatally $(16,17)$. Hence, the article by Stokholm and colleagues will definitively stimulate further research into prenatal inflammation and to those of its determinants that are amenable to modification (6).

Author disclosures are available with the text of this article at www.atsjournals.org.

Markus J. Ege, M.D., M.P.H.

Dr. von Hauner Children's Hospital

LMU Munich

Munich, Germany

and

Comprehensive Pneumology Centre Munich

German Centre for Lung Research

Munich, Germany

ORCID ID: 0000-0001-6643-3923 (M.J.E.).

\section{References}

1. Depner M, Fuchs O, Genuneit J, Karvonen AM, Hyvärinen A, Kaulek V, Roduit C, Weber J, Schaub B, Lauener R, et al.; PASTURE Study Group. Clinical and epidemiologic phenotypes of childhood asthma. Am J Respir Crit Care Med 2014;189:129-138.
2. Duhig K, Chappell LC, Shennan AH. Oxidative stress in pregnancy and reproduction. Obstet Med 2016;9:113-116.

3. Redman CW, Sargent IL. Immunology of pre-eclampsia. Am J Reprod Immunol 2010;63:534-543.

4. Rahimzadeh M, Norouzian M, Arabpour F, Naderi N. Regulatory T-cells and preeclampsia: an overview of literature. Expert Rev Clin Immunol 2016;12:209-227.

5. Figueiredo AS, Schumacher A. The T helper type 17/regulatory T cell paradigm in pregnancy. Immunology 2016;148:13-21.

6. Stokholm J, Sevelsted A, Anderson UD, Bisgaard H. Preeclampsia associates with asthma, allergy and eczema in childhood. Am J Respir Crit Care Med 2017;195:614-621.

7. Southcombe JH, Redman CW, Sargent IL, Granne I. Interleukin-1 family cytokines and their regulatory proteins in normal pregnancy and pre-eclampsia. Clin Exp Immunol 2015;181:480-490.

8. Sheikh AM, Small HY, Currie G, Delles C. Systematic review of micro-rna expression in pre-eclampsia identifies a number of common pathways associated with the disease. PLoS One 2016;11:e0160808.

9. Grieger JA, Clifton VL, Tuck AR, Wooldridge AL, Robertson SA, Gatford KL. In utero programming of allergic susceptibility. Int Arch Allergy Immunol 2016;169:80-92.

10. Stokholm J, Thorsen J, Chawes BL, Schjorring S, Krogfelt KA Bonnelykke K, Bisgaard H, Stokholm J, Thorsen J, Chawes BL, et al. Cesarean section changes neonatal gut colonization. J Allergy Clin Immunol 2016;138:881-889.

11. Canakci V, Canakci CF, Yildirim A, Ingec M, Eltas A, Erturk A. Periodontal disease increases the risk of severe pre-eclampsia among pregnant women. J Clin Periodontol 2007;34:639-645.

12. Kunnen A, van Doormaal JJ, Abbas F, Aarnoudse JG, van Pampus MG, Faas MM. Periodontal disease and pre-eclampsia: a systematic review. J Clin Periodontol 2010;37:1075-1087.

13. Boyd HA, Basit S, Harpsøe MC, Wohlfahrt J, Jess T. Inflammatory bowel disease and risk of adverse pregnancy outcomes. PLoS One 2015;10:e0129567.

14. Strachan DP. Hay fever, hygiene, and household size. BMJ 1989;299: 1259-1260.

15. Ege MJ, Bieli C, Frei R, van Strien RT, Riedler J, Ublagger E, Schram-Bijkerk D, Brunekreef B, van Hage M, Scheynius A, et al.; Parsifal Study team. Prenatal farm exposure is related to the expression of receptors of the innate immunity and to atopic sensitization in schoolage children. J Allergy Clin Immunol 2006;117:817-823.

16. Loss G, Depner M, Ulfman LH, van Neerven RJ, Hose AJ, Genuneit J, Karvonen AM, Hyvärinen A, Kaulek V, Roduit C, et al.; PASTURE study group. Consumption of unprocessed cow's milk protects infants from common respiratory infections. J Allergy Clin Immunol 2015;135:56-62.

17. Brick T, Schober Y, Böcking C, Pekkanen J, Genuneit J, Loss G, Dalphin JC, Riedler J, Lauener R, Nockher WA, et al.; PASTURE study group. $\omega-3$ fatty acids contribute to the asthma-protective effect of unprocessed cow's milk. J Allergy Clin Immunol 2016;137: 1699-1706.

Copyright () 2017 by the American Thoracic Society

\title{
Maintaining the Benefits of Pulmonary Rehabilitation The Holy Grail
}

Pulmonary rehabilitation (PR) confers benefits across multiple outcome areas for patients with chronic obstructive pulmonary disease (COPD) (1). It is a high-value multidisciplinary treatment (2) that is tailored to the needs of the individual patient according to the type of underlying disease, medical comorbidities, symptoms, exercise tolerance, functional disability, and goals; indeed, PR is true "personalized medicine" (3). The benefits of PR do wane over time, however (4), which has led to interest in strategies to maintain the gains achieved. To date, the effects of exercise-based maintenance programs after PR have been variable (5); thus, their role remains controversial. 
In this issue of the Journal, Güell and colleagues (pp. 622-629) have shown in a multicenter randomized controlled trial involving 143 patients with moderate to severe COPD (6) that a 3-year maintenance intervention after an initial 8-week outpatient PR program led to better maintenance of 6-minute-walk distance (6MWD) and Body mass index, airflow Obstruction, Dyspnea score and Exercise capacity (BODE) scores (7) over the course of 24 months compared with a control group. This trial is powerful, as it demonstrates benefits of a maintenance strategy and has the longest follow-up period of any published randomized trial of post-PR maintenance. It is also noteworthy, as the sustained improvements in BODE scores over time raise the possibility that maintenance interventions could improve patient survival (7). Sustained participation in regular exercise and maintenance of exercise capacity could also potentially have disease-modifying effects for individuals with COPD if they led to sustained increases in physical activity and/or reductions in exacerbations or hospitalizations (8). Importantly, the $66 \%$ patient adherence to the maintenance intervention in this trial at 3 years demonstrates the potential of maintenance programs to encourage patients to maintain benefits initially achieved. We therefore applaud the investigators for conducting this trial. It demonstrates the feasibility of achieving at least some sustained benefits after a short-term PR intervention, and in turn supports the recommendation of PR experts that home-based exercise in combination with hospital-based sessions should continue after PR completion. Indeed, irrespective of clinical trials, many patients want long-term access to maintenance PR, including access to exercise equipment (9). We hope that the findings of this trial will help garner support for more sustainable funding for PR programs to enable implementation of maintenance programs $(10,11)$. There are, however, several issues worthy of comment and consideration.

First, the maintenance intervention undertaken by Güell and colleagues required provision of cycle ergometers in the home for the intervention group (6). This is not feasible in all health systems beyond the research setting. Moreover, the patients in the intervention group attended supervised exercise sessions every other week at the hospital, which may not be feasible for some patients, particularly in some geographic settings. Importantly, the maintenance intervention in this trial focused primarily on exercise training. Other aspects of a comprehensive long-term rehabilitation intervention such as interactions by an occupational therapist, nutritionist, or health psychologist were lacking during the follow-up period.

Second, despite a 3-year long maintenance program, benefits in BODE score and 6MWD were sustained only at 24 months. No gains made in the initial PR program were sustained at 3 years. The reasons for this are unclear. It could perhaps relate to the substantial drop-out rate from the study over time $(>50 \%)$. The dropouts related to COPD exacerbations and hospitalizations, medical comorbidities, and other issues, some of which may not be readily preventable. A sole focus of the maintenance intervention on exercise training and progression of lung disease over time could have also influenced the lack of benefits at 3 years.

Third, it is not clear why the maintenance intervention was not associated with any significant gains in health-related quality of life (HRQOL). Patients may have experienced health issues that could have minimized HRQOL gains. Might patients have found participation in the maintenance program to be burdensome, with subsequent adverse effects on HRQOL? Patients' perceptions regarding participation in long-term maintenance PR merit further study. Fatigue, performance of activities of daily living, anxiety, and depression are also important outcomes to investigate after maintenance PR.

Fourth, patients' baseline medical comorbidities and physical activity levels were not formally assessed by Güell and colleagues (6), and few of the study patients required supplemental oxygen therapy. Therefore, it is unclear whether the findings of this study are generalizable to patients with more severe lung disease with multiple comorbidities and/or requirement for long-term oxygen therapy. Such patients may require a more multifaceted, multidisciplinary form of long-term support. One cannot assuredly extrapolate the benefits of a maintenance PR program in one setting to other patient groups.

Maintaining the benefits of PR over time is indeed a mighty task. One cannot necessarily expect the effects of a single short-term intervention such as PR to have long-lasting effects. Several barriers contribute to poor patient uptake and completion of PR (12-14). Likewise, factors such as lack of transportation, disruption of daily routine, presence or absence of family support, content and duration of the initial and maintenance program, magnitude of benefits gained from participation in and adherence to the initial PR program, disease severity, exacerbations, medical comorbidities, physical inactivity, patient motivation, and psychosocial, cultural, and geographical issues all have the potential to affect the success of post-PR maintenance programs. It is unclear whether, and to what extent, the variability of response to maintenance interventions shown in clinical trials relates to these issues. As highlighted by Güell and colleagues (6), participation in and adherence to maintenance PR is challenging, particularly for those with severely impaired exercise tolerance, dyspnea, and/or medical comorbidities that disrupt program continuity. Efforts should be made to understand and overcome patient barriers to participation and adherence.

Importantly, as well, there is substantial variability in the magnitude of individuals' responses to PR. No study to date has conclusively demonstrated specific factors that can accurately predict which patients will, vs. will not, achieve gains in PR to guide patient candidacy. In keeping with this, the magnitude of gains in $6 \mathrm{MWD}$ among the participants in the trial by Güell and colleagues (6) was widely variable both after the initial PR intervention and during the maintenance program. Indeed, patients have differential responses to PR with regard to varying outcomes (15).

Individuals who participate enthusiastically, achieve substantial benefits from PR, and see an effect in their daily lives may be more likely to maintain exercise over time and do particularly well with maintenance programs. Others are more reluctant and/or may respond less well to PR to begin with, and face barriers to initial PR participation, not to mention participation in and adherence to maintenance rehabilitation. Skilled, dedicated healthcare professionals play a major role in fostering a complex health behavior change process in PR for such patients (16). Maintenance of PR benefits over time likely does depend on whether patients achieve health-enhancing behavior change to undertake regular exercise and/or increase their daily physical activity levels and achieve enhanced self-efficacy to cope with and manage their condition. Despite its likely importance, the ability of maintenance PR programs to foster health-enhancing behavior change, and the role of behavior change per se in sustaining long-term gains after PR remains unknown. Maintenance programs with exercise training as 
the sole intervention may be insufficient to change patients' longterm daily activity levels or self-efficacy for managing their disease.

There is a pressing need to better understand and address the basis of patients' differential responses to PR to understand what maintenance intervention or interventions are likely to work best. Given the complexity of factors involved, it is likely that "one size does not fit all" in regard to maintenance PR. At this time, there is no convincing evidence that supports the use of one maintenance strategy over others. We must be cautious not to reach broad sweeping conclusions about the efficacy of maintenance PR based on data that are still somewhat limited. Varying strategies will likely be needed for individuals with varying needs and circumstances; this may include center-based rehabilitation for some and telehealthsupported home-based rehabilitation for others (17), and novel, asyet undeveloped strategies may emerge. Rather than aiming toward implementation of any particular "standard form" of maintenance that may have varying benefits in different patient groups and healthcare systems, resources for maintenance PR might be better used by providing individually targeted (18) and/or repeat interventions over time (19). Maintenance PR that varies over time by targeting specific events or issues such as worsened functional disability and/or decline in physical activity level, episodes of anxiety, depression, worsening frailty, cachexia, nutritional disturbances, exacerbations, or other medical or psychosocial complications is likely optimal. A shift to this highly individualized form of PR maintenance that would vary over the course of the patient's lifetime would require a health system paradigm shift. It would require close longitudinal follow-up of individual patients across the trajectory of illness by healthcare professionals who could note and intervene in specific issues as they arise. This is not currently readily available in most healthcare systems (20), but may be more beneficial, at least for some patients, than a predesignated set period of continuous maintenance PR after an initial PR program at a single point in time. Engaging patients in the discussion is of key importance.

\section{Author disclosures are available with the text of this article at www.atsjournals.org.}

Carolyn L. Rochester, M.D.

Section of Pulmonary, Critical Care and Sleep Medicine

Yale University School of Medicine

New Haven, Connecticut

and

Department of Internal Medicine

VA Connecticut Healthcare System

West Haven, Connecticut

Martijn A. Spruit, P.T., Ph.D., F.E.R.S.

Department of Research and Education

$\mathrm{CIRO}+$, Center of Expertise for Chronic Organ Failure

Horn, the Netherlands

and

REVAL - Faculty of Medicine and Life Sciences

Hasselt University

Diepenbeek, Belgium

and

NUTRIM School of Nutrition and Translational Research in Metabolism Maastricht University Medical Centre

Maastricht, the Netherlands

ORCID ID: 0000-0003-3822-7430 (M.A.S.).

\section{References}

1. Spruit MA, Singh SJ, Garvey C, ZuWallack R, Nici L, Rochester C, Hill K, Holland AE, Lareau SC, Man WD, et al.; ATS/ERS Task Force on Pulmonary Rehabilitation. An official American Thoracic Society/European Respiratory Society statement: key concepts and advances in pulmonary rehabilitation. Am J Respir Crit Care Med 2013;188:e13-e64.

2. Zoumot Z, Jordan S, Hopkinson NS. Emphysema: time to say farewell to therapeutic nihilism. Thorax 2014;69:973-975.

3. Wouters EF, Augustin IM. Process of pulmonary rehabilitation and program organization. Eur J Phys Rehabil Med 2011;47:475-482.

4. Carr SJ, Goldstein RS, Brooks D. Acute exacerbations of COPD in subjects completing pulmonary rehabilitation. Chest 2007;132:127-134.

5. Beauchamp MK, Evans R, Janaudis-Ferreira T, Goldstein RS, Brooks D. Systematic review of supervised exercise programs after pulmonary rehabilitation in individuals with COPD. Chest 2013; 144:1124-1133.

6. Güell MR, Cejudo P, Ortega F, Puy MC, Rodríguez-Trigo G, Pijoan Jl, Martinez-Indart L, Gorostiza A, Bdeir K, Celli B, et al. Benefits of longterm pulmonary rehabilitation maintenance program in patients with severe chronic obstructive pulmonary disease: three-year follow-up. Am J Respir Crit Care Med 2017;195:622-629.

7. Celli BR, Cote CG, Marin JM, Casanova C, Montes de Oca M, Mendez RA, Pinto Plata V, Cabral HJ. The body-mass index, airflow obstruction, dyspnea, and exercise capacity index in chronic obstructive pulmonary disease. N Engl J Med 2004;350: 1005-1012.

8. Spruit MA, Pitta F, McAuley E, ZuWallack RL, Nici L. Pulmonary rehabilitation and physical activity in patients with chronic obstructive pulmonary disease. Am J Respir Crit Care Med 2015;192:924-933.

9. Hogg L, Grant A, Garrod R, Fiddler H. People with COPD perceive ongoing, structured and socially supportive exercise opportunities to be important for maintaining an active lifestyle following pulmonary rehabilitation: a qualitative study. J Physiother 2012;58:189-195.

10. Rochester CL, Vogiatzis I, Holland AE, Lareau SC, Marciniuk DD, Puhan MA, Spruit MA, Masefield S, Casaburi R, Clini EM, et al.; ATS/ERS Task Force on Policy in Pulmonary Rehabilitation. An official American Thoracic Society/European Respiratory Society policy statement: enhancing implementation, use, and delivery of pulmonary rehabilitation. Am J Respir Crit Care Med 2015;192:1373-1386.

11. Spruit MA, Pitta F, Garvey C, ZuWallack RL, Roberts CM, Collins EG, Goldstein R, McNamara R, Surpas P, Atsuyoshi K, et al.; ERS Rehabilitation and Chronic Care, and Physiotherapists Scientific Groups; American Association of Cardiovascular and Pulmonary Rehabilitation; ATS Pulmonary Rehabilitation Assembly and the ERS COPD Audit team. Differences in content and organisational aspects of pulmonary rehabilitation programmes. Eur Respir J 2014;43:1326-1337.

12. Keating A, Lee A, Holland AE. What prevents people with chronic obstructive pulmonary disease from attending pulmonary rehabilitation?: a systematic review. Chron Respir Dis 2011;8:89-99.

13. Hayton C, Clark A, Olive S, Browne P, Galey P, Knights E, Staunton L, Jones A, Coombes E, Wilson AM. Barriers to pulmonary rehabilitation: characteristics that predict patient attendance and adherence. Respir Med 2013;107:401-407.

14. Heerema-Poelman A, Stuive I, Wempe JB. Adherence to a maintenance exercise program 1 year after pulmonary rehabilitation: what are the predictors of dropout? J Cardiopulm Rehabil Prev 2013;33:419-426.

15. Spruit MA, Augustin IM, Vanfleteren LE, Janssen DJ, Gaffron S, Pennings HJ, Smeenk F, Pieters W, van den Bergh JJ, Michels AJ, et al.; CIRO + Rehabilitation Network. Differential response to pulmonary rehabilitation in COPD: multidimensional profiling. Eur Respir J 2015;46:1625-1635.

16. Meis JJ, Bosma CB, Spruit MA, Franssen FM, Janssen DJ, Teixeira PJ, Augustin IM, Wouters EF, de Vries NK, Schols AM, et al. A qualitative assessment of COPD patients' experiences of pulmonary rehabilitation and guidance by healthcare professionals. Respir Med 2014;108:500-510.

17. Zanaboni P, Hoaas H, Aarøen Lien L, Hjalmarsen A, Wootton R. Long term exercise maintenance in COPD via telerehabilitation: a two-year pilot study. J Telemed Telecare [online ahead of print] 16 Feb 2016; DOI: $10.1177 / 1357633 \times 15625545$. 
18. Singh S. Physical activity and pulmonary rehabilitation: a competing agenda? Chron Respir Dis 2014:11:187-189.

19. Foglio K, Bianchi L, Bruletti G, Porta R, Vitacca M, Balbi B, Ambrosino N. Seven-year time course of lung function, symptoms, health-related quality of life, and exercise tolerance in COPD patients undergoing pulmonary rehabilitation programs. Respir Med 2007;101: 1961-1970.
20. Han MK, Martinez CH, Au DH, Bourbeau J, Boyd CM, Branson R, Criner GJ, Kalhan R, Kallstrom TJ, King A, et al. Meeting the challenge of COPD care delivery in the USA: a multiprovider perspective. Lancet Respir Med 2016;4:473-526.

\section{Multiscale Lung Imaging Provides New Insights into Disease Progression in the Chronic Obstructive Pulmonary Disease Lung}

The early disappearance of terminal bronchioles in the sequelae of events associated with chronic obstructive pulmonary disease (COPD) was observed in what is now considered to be a landmark publication of McDonough and colleagues using both multi-detector row computed tomography (MDCT) and micro-computed tomography (microCT) to study the lungs of subjects with panlobular (PLE) and centrilobular (CLE) emphysema (1). In comparison with control subjects, McDonough and colleagues found a reduction of airway segments detected at the limits of resolution of MDCT in both PLE and CLE (1). These reductions in the 2- to $2.5-\mathrm{mm}$ inner diameter airways observed on MDCT were accompanied by a reduction in the number of terminal bronchioles in PLE and more so in subjects with CLE studied by microCT. In this issue of the Journal, Tanabe and colleagues (pp. 630-638) extend the observations of McDonough and colleagues by assessing, in an expanded set of lung samples, the anatomic characteristics of the preterminal airways of PLE, CLE, and control subjects (2). The observations include a demonstration of an increased wall thickness and wall area percentage in CLE compared with subjects with PLE and control subjects.

One of the most interesting features of this study is that it allowed airways to be integrally studied, from branch point to branch point, cross-section, and length. This resulted in the paradoxical finding that, compared with control subjects, the length of preterminal bronchioles is reduced by 28 and $48 \%$ in CLE and PLE, respectively, whereas the lung volumes are increased by 33 and $46 \%$, an observation that needs some explanation. However, it is only paradoxical if one assumes that the emphysema pathology affects both the acinar structures and the airways homogeneously, but this is hardly the case. Integrity of lung structure is essentially ensured by the complex fiber continuum that extends from the pleura through the septal fiber nets of the acini and along the airway tree to the hilum (3). This system has the characteristics of a tensegrity structure $(4,5)$ : when one fiber of the tensed network is snapped, the entire structure becomes deformed. In the case of emphysema, the acinar fiber networks are partly disrupted, which reduces the tensile forces they exert on the proximal structures, mainly on the (pre)terminal airways that will retract toward the larger more central airways; at the same time they will withdraw from the acinar structures, thus increasing the acinar space, the hallmark of emphysema.

The observation that total wall volume of preterminal bronchioles was not maintained but reduced, despite the observation of cross-sectional thickening, in both CLE and PLE, suggests an upstream loss of airway structure coincident with the previously observed (2) disappearance of terminal airways. With this current observation of wall volume reduction in the preterminal bronchioles, there is emerging a picture of wall reduction along the length of the airway tree. Smith and colleagues have recently demonstrated that, if one is careful to assess spatially matched airway segments, on average, subjects with COPD have thinner airway walls compared with a nonsmoking control population (6). It should be noted, as discussed by Smith and colleagues, that the observation of thinned airway walls is based on a population average and is not to say that wall thickening is absent from a portion of the COPD population (6). There seems to be at least a subset of the COPD population with an airway phenotype that includes airway wall thinning starting as centrally as the segmental airways and possibly extending to the periphery, whereby the terminal bronchioles are lost.

The emergence of new imaging methodologies holds great promise for the continued exploration of this and other COPD phenotypes, and, through the ability to follow these phenomena longitudinally, disease etiologies will begin to be better understood. Although it is observed that the terminal bronchioles are reduced in length (2), it would seem difficult to know whether or not the length observed in a cored and preserved sample is truly reflective of the state of the bronchioles within the intact lung. A microCT methodology using interior tomography has been introduced (7), whereby large tissue samples can be imaged with a region of interest set to reconstruct pulmonary acini with a spatial resolution down to 1 to $2 \mu \mathrm{m}$. This methodology allows for the detailed comparison of airway and acinar anatomy ranging from the subpleural regions to the lung core (8), and airway paths can be traced from the acinus to the segmental bronchi.

Advances in MDCT allow for the imaging of the lung with a spatial resolution two to three times that of previous CT methodologies (Siemens SOMATOM Force; Siemens, Forchheim, Germany), and iterative reconstruction methods provide low-noise images with X-ray doses down to $0.1 \mathrm{mSv}$ or the dose associated with a pair of chest films (9). Novel new hyperpolarized gas methods for magnetic resonance imaging provide the tools to longitudinally follow indices associated with the terminal bronchioles (10-12). Dual-energy CT has allowed for the assessment of peripheral distributions of perfused blood volume, a surrogate for parenchymal perfusion, leading to the exploration of vascular 